\title{
Theoretical Evaluation for the Assisted Electropolymerization of a Monomer, Obtained by an Indirect Electrochemical Synthesis
}

Volodymyr V. Tkach ${ }^{1,2, *(D)}$, Marta V. Kushnir ${ }^{1}$ (D), Vira V. Kopiika ${ }^{3}$ D , Olga V. Luganska ${ }^{3}$ (D), Lyudmyla O. Omelianchyk $^{3}$ (D), Yulia V. Yeshchenko ${ }^{3}$ (D), Zholt O. Kormosh ${ }^{4}$ (D),

Viktor V. Kryvetskyi ${ }^{5(D)}$, Igor V. Kryvetskyi ${ }^{5(D)}$, Inna I. Kryvetska ${ }^{5}$, , Vitalii F. Rusnak ${ }^{5(D)}$, Bohdana Yu. Banul ${ }^{5}$ (D), Natalia M. Gordiyenko ${ }^{6}$ (D), Yulia V. Britsyna ${ }^{6}$ (D), Konon L. Bagrii ${ }^{7}$, Lyubov T.

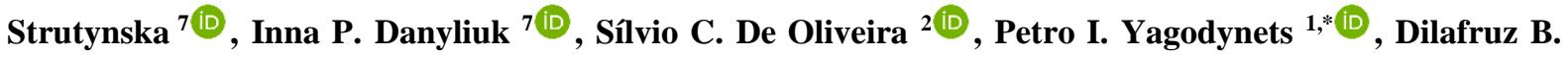
Razhabova $^{8}$ (D), Laziz N. Niyazov 8 (D)

1 Chernivtsi National University, 58000, Kotsyubyns`ky Str. 2, Chernivtsi, Ukraine; Nightwatcher2401@gmail.com (V.V.T.), marta.v.kushnir@gmail.com (M.V.K.), Ved1988mid@ rambler.ru (P.I.Y.);

2 Universidade Federal de Mato Grosso do Sul, Av. Sen. Felinto. Müller, 1555, C/P. 549, 79074-460, Campo Grande, MS, Brazil; scolive@gmail.com (S.D.O.);

3 Zaporizhzhia National University, 69600, Zhukovsky Str. 66, Zaporizhzhia, Ukraine; vkopijka@ukr.net (V.V.K.), 130805olga@gmail.com (O.V.L.), Liudmila_omelianchyk@ukr.net (L.O.O.), yeshchenko@mail.ru (Y.V.Y.);

4 Eastern European National University, 43000, Voli Ave., 13, Lutsk, Ukraine; Zholt-1971@ukr.net (Z.O.K.);

5 Bukovinian State Medical University, 58001, Teatralna Sq., 9, Chernivtsi Ukraine; kryvetskyj@bsmu.edu.ua (V.V.K.), Igor012300@gmail.com (I.V.K.), i.kryvetska@bsmu.edu.ua (I.I.K.), vitaliyrusnak@bsmu.edu.ua (V.F.R.), Banul.bohdana@bsmu.edu.ua (B.Y.B.);

6 Zaporizhzhia State Medical University, 69600, Mayakovsky Ave., 24, Zaporizhzhia, Ukraine; Natali_zp_@ukr.net (N.M.G.), brtsina@ukr.net (Y.V.B.);

7 Chernivtsi Institute of Trade and Economics of Kyiv National University of Trade and Economics, 58012, Central Sq. 9, Chernivtsi, Ukraine;kononbagriy@gmail.com (K.L.B.), Vvt4802@ukr.net (L.T.S.), Cherep_inna@ukr.net (I.P.D.);

8 Abu Ali Ibn Sino Bukhara State Medical Institute, 705018, Navoi Str., 1, Bukhara, Uzbekistan; Mirfayz200626@gmail.com(D.B.R.), laziznn@mail.ru (L.N.N.);

* Correspondence: nightwatcher2401@gmail.com(V.V.T.); ved1988mid@ rambler.ru (P.I.Y.);

Scopus Author ID 55758299100

Received: 13.05.2021; Revised: 25.07.2021; Accepted: 30.07.2021; Published: 5.09.2021

Abstract: In this work, the possibility for indirect electropolymerization of a monomer synthesized by an indirect electrosynthesis has been evaluated. Based on the reaction mechanism, the correspondent mathematical model has been developed and analyzed using linear stability theory and bifurcation analysis. It has been shown that in the case of indirect monomer electrosynthesis and electropolymerization, the polymer deposition is far more stable than for direct participation of the monomer in the electrochemical stage. The surface tends to be more developed. Yet, the electrochemical oscillations are expected to be less probable than in the case of the direct anodic process.

Keywords: conducting polymers; electropolymerization; indirect cathodic electrodeposition; electrochemical oscillations; steady stable-state.

(C) 2021 by the authors. This article is an open-access article distributed under the terms and conditions of the Creative Commons Attribution (CC BY) license (https://creativecommons.org/licenses/by/4.0/).

\section{Introduction}

Electropolymerization is one of the most used synthetic techniques for conducting polymers [1-10]. It consists of conducting polymer deposition over an electrode surface in an electrochemical process. 
Electropolymerization may be direct or indirect. In the first case, the monomer is oxidized or reduced directly, provoking a chain initiation and propagation. In the second case, the electrochemical stage yields a chain initiator, reacting with the monomer, yielding a polymer. The second path provides a more flexible conducting polymer formation, like in [1115]. For example, this is the unique possibility for polypyrrole and polythiophene formation on the cathode.

In some cases, not only polymer but also a monomer may be formed by indirect electrosynthesis. Thus, the electrochemical system will be described by an electrochemical and two chemical reactions $(1-3)$. If we consider, for simplicity, a cathodic process, it will be described as:

$$
\begin{array}{rrr}
\mathrm{A}+\mathrm{ne}- & \rightarrow \mathrm{In} & \text { (initiator electrochemical formation) (1) } \\
\mathrm{M}_{0}+\mathrm{In} & \rightarrow \mathrm{M}+\mathrm{A} & \text { (monomer indirect formation) } \\
\mathrm{nM}+\mathrm{In} & \rightarrow \mathrm{M}_{\mathrm{n}}+\mathrm{A} & \text { (polymer indirect electrodeposition) }
\end{array}
$$

As a matter of fact, the monomer, which undergoes an indirect electropolymerization on a specifically modified cathode, is also synthesized analogously, yielding a polymer. These processes may be accompanied by electrochemical instabilities (oscillatory and monotonic) $[16,17]$, capable of causing drastic changes in the resulting polymer changes.

In this work, the theoretical description for the system described above is exposed. By the mathematical modeling and analysis, it is possible to investigate the steady-state stability conditions, like also to foresee the occurrence of electrochemical instabilities affecting the system. Also, the behavior of this system will be compared to similar ones [18-21].

\section{Materials and Methods}

\subsection{System and its modeling.}

Schematically, the exposed electrochemical system will be described as on Fig. 1:

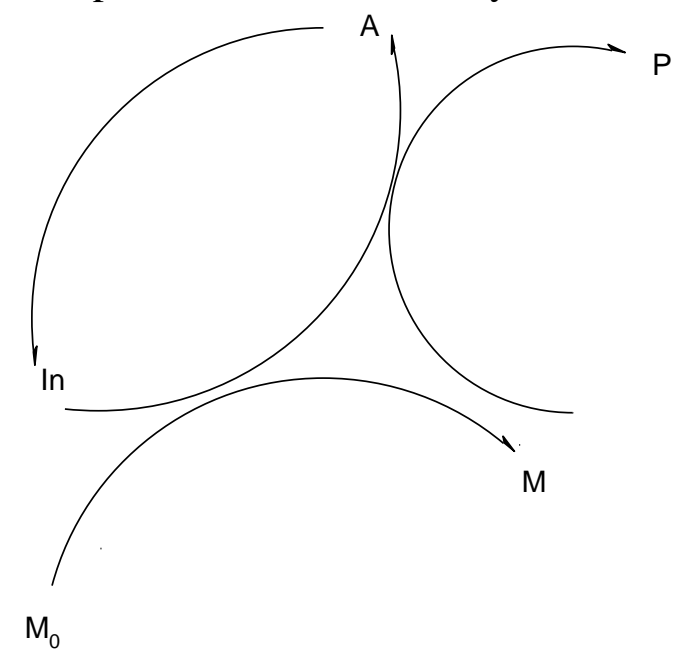

Figure 1.The scheme of the indirect monomer and polymer electrochemical synthesis.

Taking this into account, to describe the behavior of the system, we introduce three variables:

$\mathrm{c}$ - monomer precursor concentration in the pre-surface layer;

$\mathrm{m}$ - monomer concentration in the pre-surface layer;

$\mathrm{v}$ - chain initiator surface coverage degree. 
To simplify the modeling, we suppose that the reactor is intensively stirred to neglect the convection flow. Also, we assume that the background electrolyte is in excess to neglect the migration flow. The diffusion layer is supposed to be of a constant thickness, equal to $\delta$, and the concentration profile is supposed to be linear.

It is possible to show that the behavior of the electrochemical process will be described as (4):

$$
\left\{\begin{array}{c}
\frac{d c}{d t}=\frac{2}{\delta}\left(\frac{\Delta}{\delta}\left(c_{0}-c\right)-r_{m}\right) \\
\frac{d m}{d t}=\frac{2}{\delta}\left(r_{m}-r_{p}\right) \\
\frac{d v}{d t}=\frac{1}{V}\left(r_{i}-r_{m}-r_{p}\right)
\end{array}\right.
$$

Herein, $\Delta$ is the diffusion coefficient, $\mathrm{c}_{0}$ is the precursor bulk concentration, $\mathrm{V}$ is the chain initiator maximal surface concentration, and the parameters $r$ are the correspondent reaction rates, calculated as:

$$
\begin{gathered}
r_{m}=k_{m} c v \\
r_{p}=k_{p} m^{n} v \\
r_{i}=k_{i}(1-v) \exp \left(-\frac{z F \varphi_{0}}{R T}\right)
\end{gathered}
$$

The parameters $\mathrm{k}$ are the correspondent rate constants, $\mathrm{z}$ is the number of the transferred electrons, $\varphi_{0}$ is the potential slope in the double electric layer (DEL), $F$ is the Faraday number, $\mathrm{R}$ is the universal gas constant, and $\mathrm{T}$ is the absolute temperature.

In this work, the simplest system, in which the monomer doesn't contain ionic functional groups capable of influencing DEL, is investigated. Therefore, the oscillatory behavior will be caused uniquely by the behavior on the electrochemical stage, and the polymer deposition will be realized in an efficient manner, as shown below.

\section{Results and Discussion}

To investigate the indirect cathodic electropolymerization behavior of an indirectly synthesized monomer, we analyze the equation-set (4), taking into account the algebraic relations $(5-7)$, using linear stability theory. The steady-state Jacobian matrix members for this system will be exposed as (8):

$$
\left(\begin{array}{lll}
a_{11} & a_{12} & a_{13} \\
a_{21} & a_{22} & a_{23} \\
a_{31} & a_{32} & a_{33}
\end{array}\right)
$$

in which:

$$
\begin{gathered}
a_{11}=\frac{2}{\delta}\left(-\frac{\Delta}{\delta}-k_{m} v\right) \\
a_{12}=0 \\
a_{13}=\frac{2}{\delta}\left(-k_{m} c\right) \\
a_{21}=\frac{2}{\delta}\left(k_{m} v\right) \\
a_{22}=\frac{2}{\delta}\left(-n k_{p} m^{n-1} v\right) \\
a_{23}=\frac{2}{\delta}\left(k_{m} c-k_{p} m^{n}\right) \\
a_{31}=\frac{1}{V}\left(-k_{m} c\right)
\end{gathered}
$$




$$
\begin{gathered}
a_{32}=\frac{1}{V}\left(-n k_{p} m^{n-1} v\right) \\
a_{33}=\frac{1}{V}\left(-k_{i} \exp \left(-\frac{z F \varphi_{0}}{R T}\right)+j k_{i}(1-v) \exp \left(-\frac{z F \varphi_{0}}{R T}\right)-k_{m} c-k_{p} m^{n}\right)(17)
\end{gathered}
$$

As in $[13,14]$, the oscillatory behavior for this system is possible, and it will be caused uniquely by influences of the electrochemical reduction stage on DEL capacitances, described by the positivity of main-diagonal element $j k_{i}(1-v) \exp \left(-\frac{\mathrm{zF} \varphi_{0}}{\mathrm{RT}}\right)$ (positive main-diagonal elements describe the positive callback). The oscillations are expected to be frequent, and their amplitude will strongly depend on the background electrolyte composition, including $\mathrm{pH}$.

Yet if those influences aren't strong enough to influence the system's behavior, the steady-state stability is safeguarded. It may be proved as shown below. To investigate the steady-state stability in this system, we apply the Routh-Hurwitz stability criterion to the equation-set (4). Avoiding the cumbersome expressions, we introduce new variables, rewriting the determinant as (18):

$$
\frac{4}{\delta^{2} V}\left|\begin{array}{ccc}
-\kappa-\Xi & 0 & -\Lambda \\
\Xi & -P & \Lambda-\Sigma \\
-\Xi & -P & -\Omega-\Lambda-\Sigma
\end{array}\right|
$$

Opening the brackets and applying the Det $\mathrm{J}<0$ conditions, salient from the criterion, we obtain the steady-state stability requisite, exposed as (19):

$$
-(\kappa-\Xi)(2 P \Lambda+P \Omega)<2 \Lambda \Xi P
$$

Considering that all of the parameters mentioned in the inequation (19), accept of $\Omega$, are always positive, the right side of the expression (19) is always positive, and the left side is always negative if $\Omega$ is maintained positive. As the parameter $\Omega=k_{i} \exp \left(-\frac{z F \varphi_{0}}{R T}\right)-$ $j k_{i}(1-v) \exp \left(-\frac{z F \varphi_{0}}{R T}\right)$ is positive for the negative values of $\mathrm{j}$, defining the fragility of the influences of the electrochemical stage on DEL ionic force, conductivity, and impedance, the steady-state stability condition is warranted to maintain stability if $\Omega$ is positive.

This defines an efficient conducting polymer deposition. The material is formed as a well-developed cabbage-like film, centered on the active sites of the initiator formation.

The conductivity of the polymeric material will be strongly dependent on both the monomer or initiator nature.

If the initiator has non-metallic nature (for example, nitrite, sulfite), the polymer adhesion over the cathode surface is augmented, but the conductivity remains diminished. Changing the electrode polarity, the polymer is doped, preserving both the high conductivity of a doped CP or the developed surface of a cathodically deposited conducting macromolecule.

Yet if the initiator has metallic nature (manganese, vanadium, rhenium, and other, generally $\mathrm{d}$ - and f-element derivatives), the electropolymerization yields, in fact, a hybrid material with highly developed catalytic properties. It may be additionally doped by changing the polarity.

As for the proper electrosynthesis process, it is either diffusion or kinetically controlled.

The monotonic instability in this system is possible. It is manifested by an $\mathrm{N}$-shaped fragment of the voltammogram. Its condition for this case is Det $\mathrm{J}=0$, or (20):

$$
-(\kappa-\Xi)(2 P \Lambda+P \Omega)=2 \Lambda \Xi P
$$


This model describes the case in which the cathodic reaction, yielding chain initiator, is realized on the surface. If the reaction is realized in the solution, the electrochemical reaction will not be accompanied by oscillatory and monotonic stability, as shown in [13].

\section{Conclusions}

From the theoretical evaluation of the indirect electrochemical polymerization of an indirectly electrosynthetized monomer, it has been possible to conclude that the indirect electropolymerization of an indirectly electrosynthetized monomer tends to be more stable than the direct electrooxidation of the precursor and the monomer in the same conditions. As for the polymerization, it yields a well-developed macromolecule, with a cabbage-like morphology, centered on an initiator generation active sites. The electrochemical process tends to be either diffusion or kinetically controlled. The conductivity of the polymer depends on either monomer or initiator nature due to the possibility of metal-polymer formation in the case of metal derivative used as an initiator. The oscillatory behavior in this system is possible but less probable than for direct electropolymerization. It is only caused by the double electric layer influences of the electrochemical stage.

\section{Funding}

This research received no external funding.

\section{Acknowledgments}

This research has no acknowledgment.

\section{Conflicts of Interest}

The authors declare no conflict of interest.

\section{References}

1. Joshi, N.C.; Malik, S.; Gururani, P. Utilization of Polypyrrole/ZnO Nanocomposite in the Adsorptive Removal of $\mathrm{Cu}^{2+}, \mathrm{Pb}^{2+}$ and $\mathrm{Cd}^{2+}$ Ions from Wastewater. Letters in Applied NanoBioScience 2021,10, 23392351, https://doi.org/10.33263/LIANBS103.23392351.

2. Samyn, L.M.; Babu, R.S.; Devendiran, M.; de Barros, A.L.F. Electropolymerization of p-phenylenediamine films on carbon fiber fabrics electrode for flexible supercapacitors: surface and electrochemical characterizations. Ionics 2020, 26, 3041-3050,https://doi.org/10.1007/s11581-020-03562-0.

3. Bagheri, A.; Hassani Marand, M. Voltammetric and Potentiometric Determination of $\mathrm{Cu} 2+\mathrm{Using}$ an Overoxidized Polypyrrole Based Electrochemical Sensor. Russian Journal of Electrochemistry 2020, 56, 453-461,https://doi.org/10.1134/S1023193520060026.

4. Yu, S.; Piao, H.; Rejinold, N.S.; Jin, G.; Choi, G.; Choy, J.-H. Niclosamide-Clay Intercalate Coated with Nonionic Polymer for Enhanced Bioavailability toward COVID-19 Treatment. Polymers 2021, 13, https://doi.org/10.3390/polym13071044.

5. Liu, X.; Liu, J. Biosensors and sensors for dopamine detection. View 2021, 2, https://doi.org/10.1002/VIW.20200102.

6. Sabbaghi, N.; Noroozifar, M.; Kerman, K. Nanocomposite of Ellagic Acid with Multi-Walled Carbon Nanotubes for the Simultaneous Voltammetric Detection of Six Biomolecules. C 2021, 7, https://doi.org/10.3390/c7020043.

7. Manjunatha, J.G. Poly (Adenine) Modified Graphene-Based Voltammetric Sensor for the Electrochemical Determination of Catechol, Hydroquinone and Resorcinol. The Open Chemical Engineering Journal 2020, 14, 52-62,https://doi.org/10.2174/1874123102014010052.

8. Ahmad, K.; Kumar, P.; Mobin, S.M. A highly sensitive and selective hydroquinone sensor based on a newly designed $\mathrm{N}-\mathrm{rGO} / \mathrm{SrZrO} 3$ composite. Nanoscale Advances 2020, 2, 502511,https://doi.org/10.1039/c9na00573k. 
9. Romero-Montero, A.; del Valle, L.J.; Puiggalí, J.; Montiel, C.; García-Arrazola, R.; Gimeno, M. Poly(gallic acid)-coated polycaprolactone inhibits oxidative stress in epithelial cells. Materials Science and Engineering: C 2020, 115,https://doi.org/10.1016/j.msec.2020.111154.

10. Zamudio-Cuevas, Y.; Andonegui-Elguera, M.A.; Aparicio-Juárez, A.; Aguillón-Solís, E.; Martínez-Flores, K.; Ruvalcaba-Paredes, E.; Velasquillo-Martínez, C.; Ibarra, C.; Martínez-López, V.; Gutiérrez, M.; GarcíaArrazola, R.; Hernández-Valencia, C.G.; Romero-Montero, A.; Hernández-Valdepeña, M.A.; Gimeno, M.; Sánchez-Sánchez, R. The enzymatic poly(gallic acid) reduces pro-inflammatory cytokines in vitro, a potential application in inflammatory diseases. Inflammation 2021, 44, 174-185, https://doi.org/10.1007/s10753-02001319-5.

11. Jung, Y.; Singh, N.; Choi, K.S. Cathodic Deposition of Polypyrrole Enabling the One-Step Assembly of Metal-Polymer Hybrid Electrodes, Angew. Chem. Int. Ed. 2009, 121, 8481-8484, https://doi.org/10.1002/ange.200903596.

12. Ziyatdinova, G.; Guss, E.; Morozova, E.; Budnikov, H.; Davletshin, R.; Vorobev, V.; Osin, Y. Simultaneous voltammetric determination of gallic and ellagic acids in cognac and brandy using electrode modified with functionalized SWNT and poly(pyrocatechol violet). Food Analytical Methods 2019, 12, 2250-2261, https://doi.org/10.1007/s12161-019-01585-6.

13. Bouabdallaoui, M.; Aouzal, Z.; El Guerraf, A.; Ben Jadi, S.; Bazzaoui, M.; Wang, R.; Bazzaoui, E.A. Influence of polythiophene overoxidation on its physicochemical properties and corrosion protection performances. $\quad$ Materials Today: $\quad$ Proceedings $\quad \mathbf{2 0 2 0}, \quad 31, \quad$ S69-S74, https://doi.org/10.1016/j.matpr.2020.06.067.

14. Pinto, M.M.F.X.; Leyva, M.E.; Alencar de Queiroz, A.A.; Maron, L.B. Electropolymerization of polyaniline nanowires on poly(2-hydroxyethyl methacrylate) coated Platinum electrode.Polímeros 2020, 30, https://doi.org/10.1590/0104-1428.02020.

15. Yang, P.; Zhang, S.; Chen, X.; Liu, X.; Wang, Z.; Li, Y. Recent developments in polydopamine fluorescent nanomaterials. Materials Horizons 2020, 7, 746-761, https://doi.org/10.1039/c9mh01197h.

16. Das, I.; Goel, N.; Agrawal, N.R.; Gupta, Growth patterns of dendrimers and electric potential oscillations during electropolymerization of pyrrole using mono-and mixed surfactants. J. Phys. Chem. B 2010, 114, 12888-12896, https://doi.org/10.1021/jp105183q.

17. Das, I.; Goel, N.; Gupta, S.K.; Agrawal, N.R. Electropolymerization of pyrrole: Dendrimers, nano-sized patterns and oscillations in potential in presence of aromatic and aliphatic surfactants. Journal of Electroanalytical Chemistry 2012, 670, 1-10, https://doi.org/10.1016/j.jelechem.2012.01.023.

18. Tkach, V.V.; Kushnir, M.V., de Oliveira, S.C.; Ivanushko, Y.G.; Tkach. V.O.; Mytrofanova, H.Y.; Zadoia, A.O.; Yagodynets, P.I.; Kormosh, Z.O.; Luganska, O.V.; Pochenchuk, G.M.Theoretical Description for Copper (II) Electrochemical Determination and Retention on a 1(2-pyridilazo)-2-naphthole-Modified Anode, Lett. Appl. NanoBioSci. 2021, 10, 2078-2084, https://doi.org/10.33263/LIANBS102.20782084.

19. Tkach, V.V.; Storoshchuk, N.M.; Romaniv, L.V.; De Oliveira, S.C.; Luganska, O.V.; Gala, H.B.; Tchikuala, E.F.; Yagodynets, P.I. The theoretical evaluation of the poly(3,4-dimetylpyrrole) cathodic electrodeposition assisted by manganate ions. Vietnam Journal of Chemistry 2018, 56, 440-444, https://doi.org/10.1002/vjch.201800027.

20. Tkach, V.; Kushnir, M.; Storoshchuk, N.; Ivanushko, Y.; de Oliveira, S.; Yagodynets’', P.; Kormosh, Z. The Theoretical Description for the Confection of the Novel Thiourea-Based Active Surface for Cathodic Conducting Polymer Deposition. Appl. J. Env. Eng. Sci.2020, 6, 143-148. https://doi.org/10.48422/IMIST.PRSM/ajees-v6i2.18543.

21. Tkach, V.; Kushnir, M.; Ivanushko, Y.; Bocharov, A.V.; Kovalchuk, P.Y.; de Oliviera, S.C.; Yagodynets, P.I.; Kormosh, Z.O.; dos Reis, L.V.The theoretical description for the electrochemical determination of 4-4'dihydroxyazobenzene, assisted by a composite of squarainedye with cobalt (iii) oxyhydroxide in pair with cobalt (iv) oxide. Appl. J. Env. Eng. Sci. 2021, 7, 55-62, https://doi.org/10.48422/IMIST.PRSM/ajeesv7i1.23046. 